\title{
Genotype identification and inference of genetic relatedness among different purpose grape varieties and rootstocks using microsatellite markers
}

\author{
Ajitpal Singh ${ }^{1}$, Krishan Kumar ${ }^{3}$, Manav Indra Singh Gill ${ }^{1 \star}$, Parveen Chhuneja ${ }^{2}$, Naresh Kumar \\ Arora $^{1}$ and Kuldeep Singh ${ }^{2}$
}

\author{
${ }^{1}$ Department of Fruit Science, Punjab Agricultural University, Ludhiana - 141004, Punjab, India. \\ ${ }^{2}$ School of Agricultural Biotechnology, Punjab Agricultural University, Ludhiana, Punjab -141004, India. \\ ${ }^{3}$ Punjab Agricultural University Regional Research Station, Abohar -152116, India.
}

Accepted 16 October, 2012

\begin{abstract}
Twenty-seven (27) grape genotypes representing different grape groups namely table, wine, juice grapes and rootstocks with present or potential future importance for sub-tropical viticulture were characterized with 29 microsatellite markers spanning over 15 linkage groups of 'Syrah' $\times$ 'Grenache' linkage map. The objective of the investigation was to establish the unique molecular identity of the promising genotypes and to know the diversity status among them. The study revealed that most of the markers were highly informative and polymorphism information content (PIC) of 21 out of total 29 markers was $\geq 0.8$. The use of two simple sequence repeat (SSR) markers was sufficient enough to resolve the differences among all the grape genotypes. The unweighted Neighbour-Joining tree generated using DARwin $\mathbf{5 . 0}$ software classified the germplasm into three different clusters. The grouping of the different genotypes in the tree had distinct order. Genotypes derived from the same species were in one group, while the genotypes having both or one parents common in their pedigree formed separate group. Likewise, the rootstocks were clearly differentiated from grape varieties. However, the varieties could not be differentiated into table, juice and wine types. The findings of the study will be helpful in authentication of the genotypes and their use in the future grape breeding programmes.
\end{abstract}

Key words: Vitis species, table, juice, wine varieties, rootstocks, DNA fingerprinting, diversity analysis.

\section{INTRODUCTION}

Grape (Vitis vinifera L.) is one of the unique fruit crops being cultivated in temperate, sub-tropical and tropical regions of the world. The wide scale adoption of grape in diverse climatic conditions has been possible due to the existence of more than 1000 grape varieties worldwide. Thus, the molecular marker analysis to know diversity/ relatedness of grape germplasm holds utmost signifycance. Moreover, the unambiguous identification of the promising grape genotypes is essential for their proper management and for ensuring true to type distribution of

${ }^{\star}$ Corresponding author. E- mail: misgill@pau.edu. Tel/Fax: +91 1612401421. of the planting material to the growers (Laucou et al., 2011). Similarly, the knowledge of the genetic diversity present among them is a necessary pre-requisite for their utilization in the grape breeding programme (Aradhya et al., 2003).

The molecular markers have the potential to resolve genetic differences among genotypes at DNA level and hence, determine the level of diversity among the genotypes. Among the molecular markers, microsatellites or simple sequence repeat (SSR) markers are the most suitable for the purpose due to their co-dominant nature, hyper variable number of repeats, high frequency and abundance in selectively neutral region (Aradhya et al., 2003). Highly saturated linkage maps based on microsatellite markers alone (Adam Blondon et al., 2004; Doligez et al., 
2006; Gaspero et al., 2007 ) or their integration with other type of markers (Vezzulli et al., 2008) are available in grapes. Microsatellite markers have proved to be useful in grapes for resolving the identity of related genotypes (Jahanke et al., 2007), fingerprinting (Regner et al., 2001; Riaz et al., 2008; Prins et al., 2009) and diversity analysis of cultivars (Martinez et al., 2006; Riaz et al., 2008; Schneider et al., 2009; Patricia et al., 2009; Papanna et al., 2009), rootstocks (Upadhyay et al., 2007) and cultivars, rootstocks and interspecific hybrids (Laucou et al., 2011).

Keeping in view the potential of the SSR markers, 27 promising grape genotypes were analyzed in the present investigation with these markers. The objectives of the study were to establish the unique molecular identity of different purpose promising grape genotypes and to determine the genetic diversity among selected genotypes.

\section{MATERIALS AND METHODS}

\section{Plant material}

The present investigation on molecular marker analysis was conducted at Punjab Agricultural University, Ludhiana (Punjab), India, in 27 grape genotypes comprising of recommended/ promi-sing table, wine, juice grape varieties and rootstocks. The details of grape genotypes used in the present study along with their parentage and source of collection are shown in Table 1. From the enlisted genotypes, the table grapes viz., 'Perlette' and 'Beauty seedless' and wine grape cv. Punjab Purple $(H$ 516) have already been recommended for cultivation under sub-tropical climate.

\section{DNA extraction}

The freshly collected young leaves of different genotypes were grounded into powder in liquid nitrogen. The samples were processed using cetyl trimethyl ammonium bromide (CTAB) containing polyvinylpyrrolidone as described by Lodhi et al. (1994) with some modifications. Briefly, the chloroform extracted supernatant was treated with RNase $\left(5 \mu \mathrm{ml}^{-1}\right)$ at $37^{\circ} \mathrm{C}$ for $1 \mathrm{~h}$. The DNA from the supernatant was precipitated with the help of chilled isopropanol ( 0.70 volume of the supernatant) and dried pellets were dissolved in $1 X$ TE (Tris EDTA) buffer. The quantity and quality of the DNA samples was checked using agarose $(0.8 \%)$ gel electrophoresis in $0.5 \mathrm{X}$ Tris Borate EDTA (TBE) buffer.

\section{Microsatellite amplification}

The 29 microsatellite markers used in this study were selected from 15 linkage groups of 'Syrah' $\times$ 'Grenache' linkage map (Adam Blondon et al., 2004). The primers used for molecular analysis along with their respective linkage groups are shown in Table 2. The polymerase chain reaction (PCR) mixture $(20 \mu \mathrm{l})$ contained 16 ng DNA, $1.5 \mathrm{mM} \mathrm{MgCl} 2,0.2 \mathrm{mM}$ deoxynucleotide triphosphates (dNTPs), $0.5 \mu \mathrm{M}$ primer (Forward and reverse each) and $1 \mathrm{U}$ Taq polymerase (Promega, USA). The thermal cycling conditions included: 1 cycle of initial denaturation at $94^{\circ} \mathrm{C}$ for $4 \mathrm{~min}$, followed by 35 cycles of $94^{\circ} \mathrm{C}$ for $1 \mathrm{~min}, 56$ to $62^{\circ} \mathrm{C}$ for $1 \mathrm{~min}$ and $72^{\circ} \mathrm{C}$ for $1 \mathrm{~min}$ with a final extension of $72^{\circ} \mathrm{C}$ for $6 \mathrm{~min}$. The PCR products were re- solved on $8 \%$ non-denaturing polyacrylamide gel using $0.5 \mathrm{X}$ TBE buffer. For staining the gel, $80 \mu \mathrm{l}$ ethidium bromide $\left(10 \mathrm{mg} \mathrm{ml}^{-1}\right)$ was added directly to the buffer in the lower chamber of the CBS Scientific, USA, PAGE assembly which allowed us to check the resolution of markers at frequent intervals and in turn get the best resolution.

\section{Data recording and analysis}

The amplified bands were scored in the binary matrix as 1 (presence) or 0 (absence). The alleles in each primer were enumerated according to their size. The easily scorable amplified DNA fragment (band) at the top of the gel was numbered as first and the lowest band as the last one. The polymorphism information content (PIC) of the markers was estimated using the formula, $\mathrm{PIC}=1$ $\sum \mathrm{Pij}^{2}$ given by Nei (1987), where, $\mathrm{P}_{\mathrm{ij}}$ is the frequency of $\mathrm{j}^{\text {th }}$ allele in $i^{\text {th }}$ primer and summation extends from 1 to ' $n$ ' patterns. The genetic relatedness among the selected grape genotypes was calculated using dice coefficient of association and the tree was constructed through unweighted Neighbour-Joining tree method using software package DARwin 5.0 (Perrier et al., 2003). The stability of the tree was ascertained through 1000 bootstraps. Beside this, principal coordinate analysis using the same software (DARwin 5.0) was also followed to complement the cluster analysis.

\section{RESULTS AND DISCUSSION}

\section{Microsatellite polymorphism}

The results for the number of alleles per marker are shown in Table 2. The amplification of 29 SSR markers in the genomes of 27 different grape genotypes yielded a total of 375 alleles. The number of alleles determines the polymorphism content of a marker (Crespan et al., 1999). All the makers were highly polymorphic and the number of alleles per locus ranged from 4 (VVIN70) to 23 (VMC8G9) with an average of 12.93 alleles per locus (Table 2).

The microsatellite polymorphism depends upon the medium used for resolving the amplified product (Nagaty and El-Assal, 2011). Among the resolving media, agarose (Nagaty and El-Assal, 2011), metaphor (Lal et al., 2008), polyacrylamide (Upadhyay et al., 2007) and polymer based capillary gel (Adam Blondon et al., 2004; Laucou et al., 2011) have been used for separating the amplified products in the past. Out of these, relatively less microsatellite polymorphism is obtained when the amplified products are separated on either agarose or metaphor. The comparison of the results with previous studies performed on high resolution media (polyacrylamide/polymer based capillary gel electrophoresis), also showed variation for the mean number of alleles per locus. The mean number of alleles per locus (12.93) obtained in our study was higher than that of 8.0 alleles/locus in the studies of Upadhyay et al. (2007) on 21 different rootstocks with polyacrylamide gel electrophoresis. However, in our findings the alleles/locus were lower than 26.0 alleles/locus, as demonstrated in the studies conducted by Laucou et al. (2011) on 4370 accessions representing $V$. vinifera ssp. sylvestris and sativa, 
Table 1. Grape germplasm used for microsatellite marker analysis.

\begin{tabular}{|c|c|c|}
\hline Variety/rootstock & Parentage/specie & Source of collection \\
\hline \multicolumn{3}{|l|}{ Table grape } \\
\hline A $35-1$ & 'Black Champa' × 'Thompson Seedless' (V. vinifera) & NRC grapes, Pune ${ }^{a}$ \\
\hline Bangalore Blue & Vitis $\times$ Labruscana & NRC grapes, Pune ${ }^{a}$ \\
\hline Beauty Seedless & V. vinifera & NRC grapes, Pune ${ }^{a}$ \\
\hline Cardinal & 'Tokay' × 'Ribier' ( V. vinifera) & NRC grapes, Pune ${ }^{a}$ \\
\hline Convent Large Black & V. vinifera & NRC grapes, Pune ${ }^{a}$ \\
\hline Himrod & 'Ontariao' × 'Sultana' ( V. vinifera) & NRC grapes, Pune ${ }^{a}$ \\
\hline H 144 & 'Cheema Sahebi' × 'Catawba' $(V$. vinifera $\times$ V. labrusca $)$ & ARI, Pune $e^{b}$ \\
\hline Muscat Hamburg & 'Muscat of Alexandria' × 'Trollinger Schiava Grossa' ( $V$. vinifera) & NRC grapes, Pune ${ }^{a}$ \\
\hline Perlette & 'Scolokertek Hiralyonje 26’ × 'Sultanina Marble' (V. vinifera) & UC, Riverside $\mathrm{e}^{\mathrm{e}}$ \\
\hline Sharad Seedless & A mutant of 'Kishmish Chorni' ( $V$. vinifera) & NRC grapes, Pune ${ }^{a}$ \\
\hline
\end{tabular}

\section{Wine grape}

Cabernet Sauvignon

Chardonnay

Chasan B

Cinsault

Madeleine Angevine

Portan

Punjab Purple (H516)

Shiraz

'Cabernet Franc' × 'Sauvignon Blanc' ( $V$. vinifera)

'Pinot Noir' $\times$ 'Gouais' ( V. vinifera)

'Listan' $\times$ 'Pinot' ( $V$. vinifera)

V. vinifera

'Malingre Précoce' × 'Madeleine Royale' ( $V$. vinifera)

'Grenache Noir' × 'Blauer Portugieser' ( $V$. vinifera)

'Catawba' × 'Beauty Seedless' (V. labrusca x V. vinifera)

'Dureza' × 'Mondeuse Blanche' ( $V$. vinifera)

NRC grapes, Pune ${ }^{a}$

NRC grapes, Pune ${ }^{a}$

INRA, France ${ }^{\mathrm{d}}$

NRC grapes, Pune ${ }^{a}$

INRA, France $^{d}$

INRA, France ${ }^{d}$

ARI, Pune ${ }^{b}$

NRC grapes, Pune ${ }^{a}$

\section{Juice grape}

$\mathrm{H} 27$

'Diamond Jubilee' $\times$ 'Rubi Red' ( $V$. vinifera)

Pusa Navrang

'Angevine' $\times$ 'Rubi Red' ( $V$. vinifera)

ARI, Pune ${ }^{b}$

IARI, New Delhic

$\begin{array}{ll}\begin{array}{l}\text { Rootstocks } \\ \text { deGrasset }\end{array} & \text { V. champinii Planch. } \\ \text { Dogridge } & \text { V. champinii } \\ \text { H } 324 & \text { 'Gulabi' } \times \text { 'James' }(\text { V. vinifera } \times \text { V. rotundifolia) } \\ \text { SO4 } & \text { V. berlandieri } \times \text { V. riparia } \\ 1103 \text { P } & \text { V. berlandieri } \times \text { V. rupestris } \\ 1613 \text { C } & \text { V. solonis } \times \text { V. labrusca var. Othello } \\ 1616 \text { C } & \text { V. solonis } \times \text { V. riparia }\end{array}$

NRC grapes, Pune ${ }^{a}$ NRC grapes, Pune ${ }^{a}$ ARI, Pune ${ }^{b}$

NRC grapes, Pune ${ }^{a}$ NRC grapes, Pune ${ }^{a}$ NRC grapes, Pune ${ }^{a}$ NRC grapes, Pune ${ }^{a}$

${ }^{a}$ National Research Centre for Grapes, Pune, Maharashtra, India; ${ }^{b}$ Agarkar Research Institute, Pune, Maharashtra, India; ${ }^{\mathrm{C}}$ Indian Agriculture Research Institute, New Delhi, India; 'Institut de la Recherche Agronomique, France; 'University of California, Riverside, USA.

interspecific hybrids and different rootstocks with capillary gel electrophoresis. Therefore, besides the resolving media, the number of Vitis species and total number of accessions of a particular species also determine the microsatellite polymorphism.

Amongst the different group of genotypes (table, wine, juice grapes and rootstocks), average maximum number of alleles were present in the wine grapes (72.2) followed by juice grapes (70.0), table grapes (69.0) and rootstocks (62.8). The range of the alleles across the 27 genotypes also showed the same trend: with maximum number of alleles being in wine grape cv. Chardonnay (82.0) and minimum in rootstock $1616 \mathrm{C}$ (56.0) (complete data not shown). The results, however, are contradictory to previous studies in grapes with SSR analysis by Laucou et al. (2011) and random amplified polymorphic DNA (RAPD) analysis by Tamhankar et al. (2001). They reported more number of alleles for rootstocks than cultivars. The discrepancy for the number of alleles for rootstocks in our study could have aroused due to lesser number of genotypes analyzed of each grape group. For instance, in the juice grapes and rootstocks, only 2 and 7 genotypes, respectively were studied. On the other hand, Laucou et al. (2011) analyzed more than 4300 acces- 
Table 2. List of SSR markers used for the analysis of grape genotypes.

\begin{tabular}{lccc}
\hline Primer & Linkage group & No. of alleles & PIC \\
\hline VMC2B3 & 1 & 5 & 0.774 \\
VMC9D3 & 1 & 10 & 0.850 \\
VMC6B11 & 2 & 12 & 0.836 \\
VVIR46 & 4 & 5 & 0.636 \\
VVII52 & 5 & 13 & 0.886 \\
VVIT68 & 5 & 8 & 0.769 \\
VVIP72 & 6 & 11 & 0.841 \\
VMC1A2 & 7 & 21 & 0.941 \\
VVIN56 & 7 & 16 & 0.897 \\
VMC1B11 & 8 & 22 & 0.945 \\
VMC6G8 & 8 & 12 & 0.856 \\
VVIB66 & 8 & 22 & 0.914 \\
VMC3D7 & 10 & 5 & 0.649 \\
VMC8D3 & 10 & 10 & 0.862 \\
VVIV37 & 10 & 21 & 0.936 \\
VMC6G1 & 11 & 13 & 0.891 \\
VVIV35 & 11 & 10 & 0.861 \\
VMC8G6 & 12 & 20 & 0.930 \\
VMC8G9 & 12 & 23 & 0.943 \\
VMC9H4.2 & 13 & 13 & 0.903 \\
VMC2C3 & 14 & 5 & 0.730 \\
VMC9C1 & 14 & 8 & 0.786 \\
VVIN70 & 14 & 4 & 0.543 \\
VMC3A9 & 17 & 11 & 0.893 \\
VMC3C11.1 & 17 & 20 & 0.926 \\
VVIP44 & 17 & 10 & 0.833 \\
VMC 8B5 & 18 & 17 & 0.917 \\
VMC3B7.2 & 19 & 18 & 0.875 \\
VVIP17.1 & 19 & 10 & 0.792 \\
\hline
\end{tabular}

sions belonging to $V$. vinifera ssp. sylvestris and sativa, interspecific hybrids and rootstocks.

\section{DNA fingerprinting}

The most desired characteristic of a molecular marker is its ability to reveal the available genetic differences among the tested individuals. The PIC of a marker indicates its power of genotype differentiation (Martin et al., 2003). In present investigation, the PIC value for the SSR markers ranged from 0.543 (VVIN70) to 0.945 (VMC1B11) (Table 2). However, 21 of the total 29 SSR markers used in the study, had PIC value $\geq 0.8$ (Table 2 ).

The available diversity among the genotypes influences the informativeness of a marker (Nagaty and El-Assal, 2011). The genotypes used in the present investigation, based on their final use, represented 4 different grape groups (table, wine, juice grapes and rootstocks). These genotypes were the derivatives of either $V$. vinifera and Vitis champinii or the hybrids of the different Vitis species involving V. vinifera, Vitis labrusca, Vitis solonis, Vitis rotundifolia, Vitis berlandieri and Vitis riparia. Therefore, the available diversity among these genotypes could have also contributed towards the high PIC value of the markers.

After analyzing the banding pattern of all the used markers, we found that the two markers namely VMC6G8 and VMC8G9, when used in combination, could differentiate all the 27 grape genotypes. Although the PIC of VMC6G8 was lower than 16 other markers and of VMC8G9 which is slightly lower than that of marker VMC1B11 (Table 2), these markers produced easy to score and strong amplification profiles. It has been previously established that certain markers are more efficient in producing stable and reproducible DNA fingerprints (This et al., 1997) and for clear cut identification of genotypes, these reliable markers should be used (Laucou et al., 2011). Therefore, the use of markers VMC6G8 and VMC8G9 will facilitate easy and efficient identification of the grape genotypes used in this study. Moreover, these two markers are different from the six universal set of 
Table 3. Primers possessing unique alleles and their suitability for fingerprinting the grape genotypes.

\begin{tabular}{|c|c|c|c|}
\hline $\begin{array}{l}\text { Microsatellite } \\
\text { marker }\end{array}$ & $\begin{array}{c}\text { Number of } \\
\text { unique alleles }\end{array}$ & $\begin{array}{c}{ }^{\mathrm{a}} \text { Position of } \\
\text { unique alleles }\end{array}$ & Suitable for fingerprinting of genotypes \\
\hline VMC9D3 & 2 & 1,9 & H144 (1); Cabernet Sauvignon (9) \\
\hline VMC6B11 & 3 & $6,8,11$ & 1613 C (6); Cabernet Sauvignon (8); Sharad Seedless (11) \\
\hline VVIR46 & 2 & 1,5 & $\mathrm{H} 27$ \\
\hline VVII52 & 1 & 11 & $1613 \mathrm{C}$ \\
\hline VVIP72 & 3 & $6,8,9$ & Punjab Purple (6); SO4 (8); Perlette (9) \\
\hline VVIN56 & 1 & 1 & $1613 \mathrm{C}$ \\
\hline VMC6G8 & 3 & $3,11,12$ & Bangalore Blue (3); 1103P (11); Portan (12) \\
\hline VVIB66 & 2 & 1,4 & SO4 (1); Portan (4) \\
\hline VMC8D3 & 1 & 4 & $\mathrm{SO} 4$ \\
\hline VMC6G1 & 1 & 11 & SO4 \\
\hline VVIN70 & 1 & 2 & $1103 \mathrm{P}$ \\
\hline VVIV35 & 1 & 8 & Dogridge \\
\hline VMC8G6 & 2 & 13,19 & H144 (13); 1103P (19) \\
\hline VMC8G9 & 1 & 3 & Cabernet Sauvignon \\
\hline VMC9H4.2 & 1 & 13 & deGrasset \\
\hline VMC9C1 & 1 & 8 & $1103 P$ \\
\hline VMC3C11.1 & 3 & $1,2,11$ & H144 (1); H27 (2); SO4 (11) \\
\hline VMC3B7.2 & 3 & $1,5,16$ & $\mathrm{H} 27$ (1); $1613 \mathrm{C}(5) ; 1103 \mathrm{P}(16)$ \\
\hline VVIP17.1 & 4 & $1,2,5,7$ & Himrod $(1,7)$; Sharad Seedless (2); Convent Large Black (5) \\
\hline
\end{tabular}

${ }^{a}$ Number refers to the allele number amplified with 1 being the allele having highest molecular weight. Total number of alleles amplified by a particular marker is shown in Table 2.

markers (VVMD5, VVMD7, VVMD27, VVS2, VrZAG62 and VrZAG79) used for cultivar identification worldwide (This et al., 2004). Therefore, the use of identified markers in the present study will broaden the choice of markers for germplasm characterization in grapes.

In addition, 19 SSR markers also produced 36 genotype specific alleles (DNA fragment of a particular size amplified only in one of the genotype). The number of unique alleles ranged from 1 (VVII52, VVIN56, VVIN 70, VMC8D3, VMC6G1, VVIV35, VMC8G9, VMC9H4.2 and VMC9C1) to 4 (VVIP17.1) (Table 3). These unique alleles were present in 6 table purpose grapes, 5 rootstocks, 3 wine grapes and 1 juice grape variety. Maximum numbers of unique alleles (5) were observed for rootstocks 'SO4' (V. berlandieri $\times$ V. riparia) and '1103 P' $(V$. berlandieri $\times V$. rupestris). The availability of these genotype specific alleles will further help in establishing the unambiguous molecular identity of the studied genotypes (Table 3). The SSR marker VMC6G8 having unique alleles for rootstock '1103P' and table grape 'Bangalore Blue' and wine grape 'Portan' is shown in Figure 1.

\section{Genetic relatedness among the genotypes}

The genetic relationship amongst the different grape genotypes is shown in the form of tree generated through DARwin 5.0 using unweighted Neighbour-Joining tree method (Figure 2). For the accurate and unbiased estimation of coefficient of similarity or dissimilarity among the grape genotypes, the number of alleles should be more than 300 (Fanizza et al., 2003). As the analysis is carried out with large number of alleles, the coefficient of variation is reduced, which brings about the stability in the tree. In the present study, 375 alleles were used for the cluster analysis, therefore, the genetic relatedness depicted among the various grape genotypes under investigation can be expected to be accurate.

The tree comprised of three major clusters. The first cluster contained 10 grape varieties of $V$. vinifera origin (Cluster I, Figure 2). The cluster was further divided into two subgroups. Four table grapes ('Cardinal', 'Muscat Hamburg', 'A35-1' and 'Convent Large Black') and 3 wine grape varieties ('Chasan B', 'Portan' and 'Madeline Angevine') constituted the subgroup I of this major cluster. The pairing among the different grape varieties in this subgroup was not influenced by their type. If the table grape cultivar 'Cardinal' was closest to the wine grape cultivar 'Chasan B' with a genetic similarity value of $52 \%$ at one end of this subgroup, the two table purpose varieties 'A35-1' and 'Convent Large Black' with a genetic similarity value of $48 \%$ paired together at the other end of this subgroup. The other table purpose and wine grapes were also arranged in the subgroup according to the percentage of genetic similarity among them (Figure 2).

In the Subgroup II of the Cluster I, 2 juice grapes namely ' $\mathrm{H} 27$ ' and 'Pusa Navrang' along with a wine grape variety 'Cinsault' were present. The juice grapes showed more proximity towards each other than the lone 


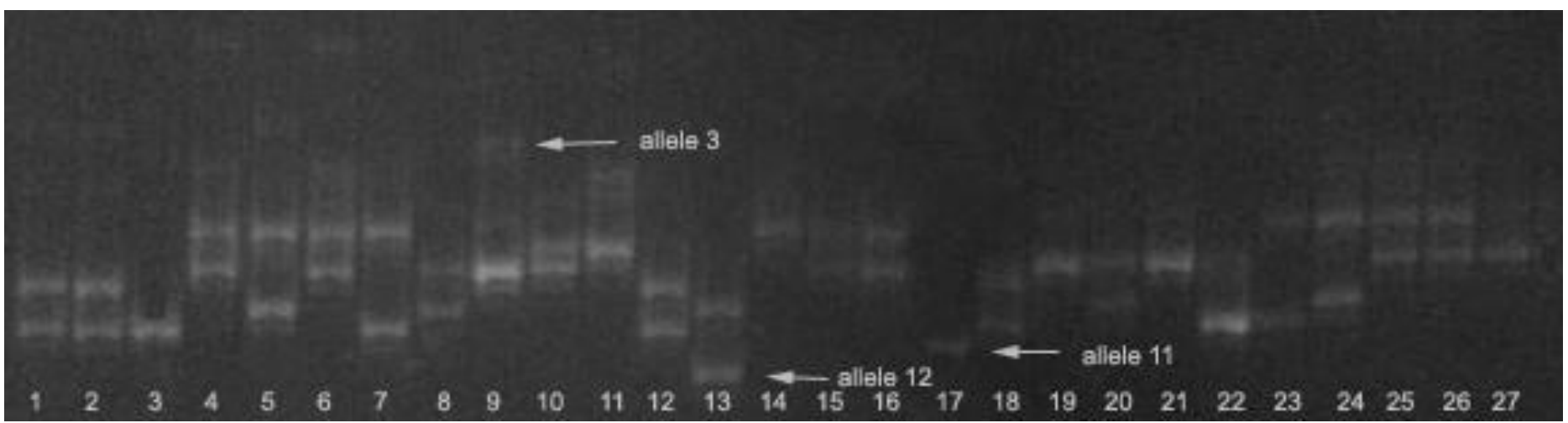

Figure 1. In vitro amplification of 27 grape genotypes for SSR marker VMC6G8 on 8\% non-denaturing polyacrylamide gel. From left to right Lanes: 1 (deGrasset); 2 (H324); 3 (SO4); 4 (Chardonnay); 5 (Cinsault); 6 (Shiraz); 7 (Cabernet Sauvignon); 8 (Sharad Seedless); 9 (Bangalore Blue); 10 (Convent Large Black); 11 (A35-1); 12 (Dogridge); 13 (Portan); 14 (Madeline Angevine); 15 (Chasan B); 16 (1613 C); 17 (1103P); 18 (1616 C); 19 (Muscat Hamburg); 20 (Punjab Purple); 21 (H 144); 22 (H 27); 23 (Pusa Navrang); 24 (Beauty Seedless); 25 (Himrod); 26 (Cardinal); 27 (Perlette). Arrows indicate the unique alleles 3, 11 and 12 suitable for the fingerprinting of Bangalore Blue (9), 1103 P (17), Portan (13).

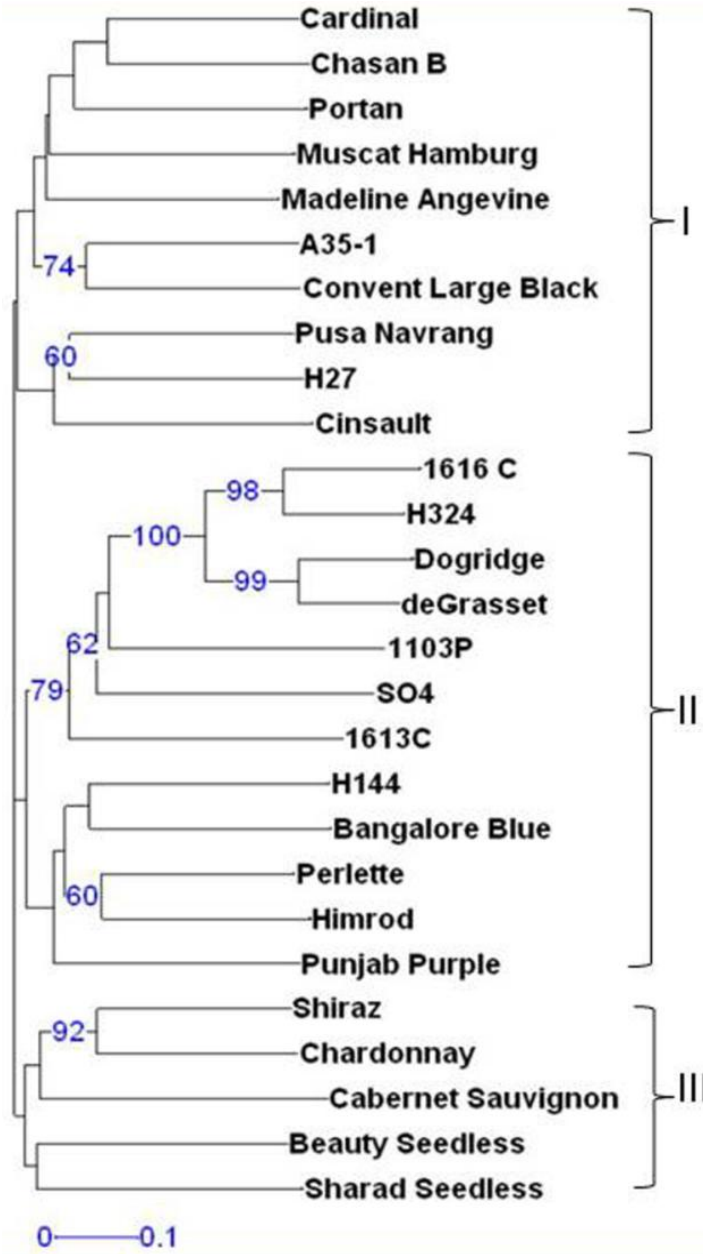

Figure 2. Genetic relationship amongst different purpose grape genotypes inferred through unweighted neighbour-joining cluster analysis using dice coefficient of association. The values on the nodes are boot strap values, indicating the percent frequency of a particular group of genotypes clubbing together in the tree. Only bootstrap values more than $50 \%$ on the nodes are shown. wine variety of this subgroup. Both the juice grape cultivars are teinturian hybrids and have common male parent 'Rubi Red' in their pedigree (Table 1).

The Cluster II was the biggest cluster among the three clusters of the tree. It was also the most species rich cluster. It contained 12 of the total 27 grape genotypes representing two Vitis species $V$. vinifera, $V$. champinii and interspecific hybrids $(V$. berlandieri $\times V$. riparia, $V$. berlandieri $\times V$. rupestris, $V$. vinifera $\times V$. rotundifolia, $V$. vinifera $\times V$. labrusca, $V$. labrusca $\times V$. vinifera, $V$. solonis $\times V$. labrusca). This cluster was further made up of two subgroups. All the rootstocks, irrespective of the species, belonged to Subgroup I of this cluster. The rootstocks 'Dogridge' and 'deGrasset', both the derivatives of the same species that is, $V$. champinii, were held together by a genetic similarity value of $74 \%$.

Similarly, 'SO4' and '1103P' had more similarity with each other, than with any other member of this subgroup. Both of these rootstocks have a female parent ( $V$. berlandieri) in common with a different male parent (Table 1). Contrary to this, rootstock ' $1613 \mathrm{C}$ ' and ' $1616 \mathrm{C}$ ', even though are the descendants of same female parent that is, V. solonis, were most distantly placed. However, ' $1616 \mathrm{C}$ ' showed higher affinity for 'H324', with which it did not have any ancestral relationship.

Another subgroup of this major cluster was formed by 4 table purpose grapes namely 'H144', 'Bangalore Blue', 'Perlette' and 'Himrod' and 1 wine grape cultivar 'Punjab Purple'. The association of this subgroup with the Subgroup I of this cluster was possibly due to sharing of $V$. labrusca genome in their pedigree. The rootstock '1613C' of Subgroup I and grape varieties such as 'H144', 'Bangalore Blue' and 'Punjab Purple' of Subgroup II have $V$. labrusca as either male or female parent in their pedigree. In this subgroup, the pair of varieties viz., ' $\mathrm{H} 144$ ' -'Bangalore Blue' and 'Perlette'-'Himrod' had a genetic similarity value of 41 and $51 \%$, respectively. 'Punjab Pur- 
Factorial analysis: Axes $1 / 2$

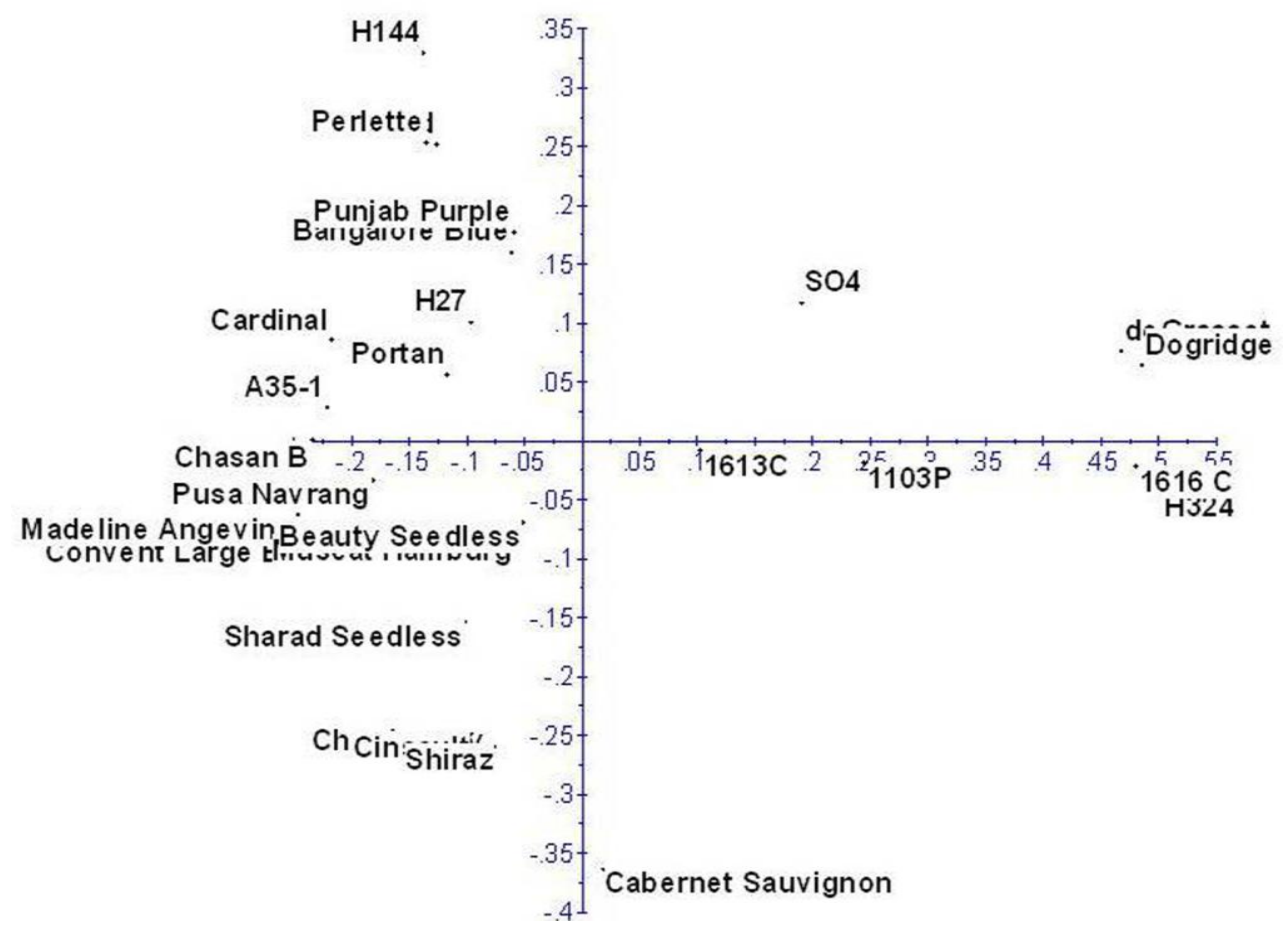

Figure 3. Principal coordinate analysis of 27 grape genotypes using DARwin 5.0.

ple', a lone wine grape cultivar in this subgroup shared 42 and $40 \%$ similarity with Perlette and Bangalore Blue, respectively.

The Cluster III contained 3 wine varieties and 2 table purpose varieties of $V$. vinifera origin. All the wine varieties ('Shiraz', 'Chardonnay' and 'Cabernet Sauvignon') formed Subgroup I of this major cluster. The table purpose cultivars 'Beauty Seedless' and 'Sharad Seedless' constituted the Subgroup II of this major cluster.

To determine the effectiveness of SSR markers for depicting the genetic variability, principal coordinate analysis was also done (Figure 3 ). The first 2 axes accounted for 52.6 and $25.7 \%$ of the total variation, respectively. All the table, wine and juice grapes were intermixed, as shown by cluster analysis. However, the rootstocks were spatially distributed.

Most of the genotypes with a few exceptions were grouped according to the available pedigree records. The genotypes clustered in different groups in the following order: genotypes descendants of the same species followed by the genotypes sharing both or at least one of the parent in their pedigree. Based on cluster analysis, the rootstocks were well differentiated from the cultivars. These results are in conformity with the studies of Lal et al. (2008) and Tamhankar et al. (2001) in grapes. Out of the 7 rootstocks used in this study, 6 were also used by Upadhyay et al. (2007) for SSR analysis. The relationship depicted among these rootstocks is in agreement with their findings. They also reported the grouping of the root stocks according to their pedigree and ' 1613 C' was also placed far apart from ' $1616 \mathrm{C}$ ' in their study as well. The results of principal coordinate analysis showed the spatial distribution of rootstocks therefore, additional data is needed for robustness and accuracy of the analysis.

The cultivars did not completely differentiate into table, wine and juice types in our study. Rather, it was only partial as the Cluster III had table and wine grapes present in two different subgroups, while the table, wine and juice grapes in Clusters I and II did not form separate sub groups according to their type. Overall, the pairing between the different genotypes in the trees was according to their parental Vitis species. For instance, all the genotypes of Clusters I and III are the derivatives of $V$. vinifera, while the Subgroup II of Cluster II contains cultivars of the interspecific origin [except Perlette and Himrod (V. vinifera)] (Table 1 and Figure 2). These results are in line with the previous reports on the cultivated varieties of $V$. vinifera by Aradhya et al. (2003), where they found the wine, table and dual purpose cultivars from different geographical origins clubbing in the same groups.

It seems that the association between the table, juice and wine grapes is at species level, as these genotypes have been domesticated from the $V$. vinifera or after its hybridisation with other Vitis species. It is the directional selection for the final product, which differentiates the 
types of grape cultivars. The artificial selection for the higher sugar in the berries, which helps in better fermentation, would have led to the formation of wine type grapes (This et al., 2006). The divergent selection for large berry size with large sized clusters, would have led to the evolution of table grapes. And, the high juice content with an ability to withstand fermentation must have led to the selection of juice grapes.

This is one of the reports, where almost all the grape groups have been analyzed with microsatellite markers. Amongst the table grape varieties, 'Perlette' and 'Beauty Seedless' are already recommended for cultivation under subtropical climate, while the rest of the cultivars also possess good characteristic features. The wine grape cultivars characterized are known worldwide for their unique flavour. Similarly, the rootstock possessed important features like resistance to salt stress and nematodes. The unambiguous molecular markers based identity of all these grape genotypes was established in this study.

The molecular marker based identity of the studied genotypes will aid in their unambiguous identification, authentication of their propagules and plantlets and in ensuring the delivery of true to type plants of a cultivar or grafted vines to the growers. The information on the genetic relatedness of grape genotypes generated in the present investigation will be useful for the horticulturists for specific identification of different genotypes to be used for future grape breeding programmes.

\section{REFERENCES}

Adam Blondon AF, Roux C, Claux D, Butterlin G, Merdinoglu D, This P (2004). Mapping 245 SSR markers on the Vitis vinifera genome: a tool for grape genetics. Theor. Appl. Genet.109:1017-1027.

Aradhya MK, Dangl GS, Prins BH, Boursiquot JM, Walker MA, Meredith CP, Simon CJ (2003). Genetic structure and differentiation in cultivated grape, Vitis vinifera L. Genet. Res. Camb. 81:179-192.

Crespan M, Botta R, Milani N (1999). Molecular characterization of twenty seeded and seedless table grape cultivars ( $V$. vinifera L.). Vitis 38:87-92.

Doligez A, Adam Blondon AF, Cipriani G, Gaspero GD, Laucou V, Merdinoglu D, Meredith CP, Riaz S, Roux C, This P (2006). An integrated SSR map of grapevine based on five mapping populations. Theor. Appl. Genet.113:369-382.

Fanizza G, Chaabane R, Lamaj F, Ricciardi I, Resta P (2003). AFLP analysis of genetic relationships among aromatic grapevines (Vitis vinifera). Theor. Appl. Genet. 107:1043-1047.

Gaspero GD, Cipriani G, Adam Blondon AF, Testolin R (2007). Linkage maps of grapevine displaying the chromosomal locations of 420 microsatellite markers and 82 markers for $R$-gene candidates. Theor. Appl. Genet.114:1249-1263.

Jahanke G, Korbuly J, Majer J, Molnar Gyorffyne J (2007). Discrimination of the grapevine cultivars Picolit and Kenknyelu with molecular markers. Scientia Hort. 114:71-73.

Lal S, Singh AK, Srivastav M, Dubey AK, Singh NK (2008). Genetic diversity assessment in Indian grape by Simple Sequence Repeat (SSR) markers. Indian J. Hort. 65(4):383-388.

Laucou V, Lacombe T, Dechesne F, Siret R, Bruno JP, Dessup M, Dessup T, Ortigosa P, Parra P, Roux C, Santoni S, Vares D, Peros JP, Boursiquot JM, This $P$ (2011). High throughput analysis of grape genetic diversity as a tool for germplasm collection management. Theor. Appl. Genet. 122:1233-1245.

Lodhi MA, Ye GN, Weeden NF, Reisch BI (1994). A simple and efficient method for DNA extraction from grapevine cultivars and Vitis species. Plant Mol. Biol. Reptr. 12:6-13.

Martin JP, Borrego J, Cabello F, Ortiz JM (2003). Characterization of Spanish grapevine cultivar diversity using sequence tagged microsatellite site markers. Genome 46:10-18.

Martinez IE, Cavagnaro PF, Masuelli RW, Zuniga M (2006). SSR based assessment of genetic diversity in South American Vitis vinifera varieties. Plant Sci. 170:1036-1044.

Nagaty MA, El Assal SED (2011). Molecular characterization and genetic relationships among some grape (Vitis vinifera L.) cultivars as revealed by RAPD and SSR markers. Europ. J. Exp. Biol. 1:71-82.

Nei M (1987). Estimation of average heterozygosity and genetic distance from a small number of individuals. Genet. 89:583-590.

Papanna N, Rao V, Murthy S, Simon L (2009). Microsatellite based genetic diversity assessment in grape (Vitis vinifera L.) germplasm and its relationship with agronomic traits. Intl. J. Fruit Sci. 9:92-105.

Patricia CSL, Riaz S, Graziani R, Dangl GS, Motoike SY, Walker MA (2009). Characterization of a Brazilian grape germplasm collection using microsatellite markers. Am. J. Enol. Vitic. 60:517-524.

Perrier X, Flori A, Bonnot F (2003). Data analysis methods. In: Hamon P, Seguin M, Perrier X, Glaszmann JC (eds.) Genetic Diversity of Cultivated Tropical Plants. Enfield, Science Publishers, Montpellier, pp. 43-76.

Prins R, Van Heerden CJ, Burger AL, Burger P, Smit WA (2009). DNA fingerprinting of table grape culivars. Acta Hort. 827:269-274.

Regner F, Stadlbauer A, Eisenheld C (2001). Molecular markers for genotyping grapevine and for identifying clones of traditional varieties. Acta Hort. 546:331-341.

Riaz S, Tenscher AC, Smith BP, Ng DA, Walker MA (2008). Use of SSR markers to assess identity, pedigree and diversity of cultivated muscadine grapes. J. Am. Soc. Hort. Sci.133:559-568.

Schneider A, Torello Marinoni D, Raimond S, Boccacci P, Gambino G (2009). Molecular characterization of wild grape populations from North-western Italy and their genetic relationship with cultivated varieties. Acta Hort. 827:211-216.

Tamhankar SA, Patil SG, Rao VS (2001). Assessment of the genetic diversity of some important grape genotypes in India using RAPD markers. Vitis 40:157-161.

This P, Cuisset C, Boursiquot JM (1997). Development of stable RAPD markers for the identification of grapevine rootstocks and the analysis of genetic relationships. Am. J. Enol. Vitic. 48:492-501.

This $P$, Jung A, Boccacci $P$, Borrego J, Botta R, Costantini L, Crespan M, Dangl GS, Eisenheld C, Ferreira-Monteiro F, Grando S, Ibanez J, Lacombe $T$, Laucou V, Magalhaes R, Meredith CP, Milani N, Peterlunger E, Regner F, Zulini L, Maul E (2004). Development of a standard set of microsatellite reference alleles for identification of grape cultivars. Theor. Appl. Genet. 109:1448-1458.

This P, Lacombe T, Thomas MR (2006). Historical origins and genetic diversity of wine grapes. Trends Genet. 22:511-519.

Upadhyay A, Saboji MD, Reddy S, Deokar K, Karibasappa GS (2007). AFLP and SSR marker analysis of grapevine rootstocks in Indian grape germplasm. Scientia Hort. 112:176-183.

Vezzulli S, Troggio M, Coppola G, Jermakow A, Cartwright D, Zharkikh A, Stefanini M, Grando MS, Viola R, Adam Blondon AF, Thomas M, This $P$, Velasco $R$ (2008). A reference integrated map for cultivated grapevine (Vitis vinifera L.) from three crosses, based on 283 SSR and 501 SNP-based markers. Theor. Appl. Genet.117:499-511. 